\title{
CPFD simulation of enhanced cement raw meal fluidization through mixing with coarse, inert particles
}

\author{
Nastaran Ahmadpour Samani ${ }^{1}$ Chameera K. Jayarathna ${ }^{2}$ Lars-Andre Tokheim ${ }^{3}$ \\ ${ }^{1}$ Department of Process, Energy and Environmental Technology, University of South-Eastern Norway, \\ 222129@student.usn.no \\ ${ }^{2}$ SINTEF Industry, chameera. jayarathna a sintef . no \\ ${ }^{3}$ Department of Process, Energy and Environmental Technology, University of South-Eastern Norway, \\ Lars.A. Tokheimeusn. no
}

\begin{abstract}
In the current work, computational particle and fluid dynamics (CPFD) simulations are used to study an electrically heated bubbling fluidized bed (BFB) used as a calciner in a cement manufacturing process, applying a binary-particle fluidization system. Owing to the fine particle size $(0.2-180 \mu \mathrm{m})$ of the limestone used as a raw meal in the cement kiln process, a conventional bubbling fluidized bed may be difficult to apply due to particle cohesion causing poor fluidizability of the particles smaller than $30 \mu \mathrm{m}$. In the current study, to enhance the fluidization of the raw meal particles, they are mixed with coarse $(550-800 \mu \mathrm{m})$, inert particles. The aggregation and clustering of the fine particles will decrease due to collisions with inert coarse particles, and hence a more homogeneous distribution of raw meal particles may be achieved. The inert particles will also provide a thermal energy reservoir through their heat capacity and thereby contribute to a very stable bed temperature, which is advantageous in the control of the process. After the raw meal particles have been calcined, they have to be separated from the coarse, inert particles. This can be done by increasing the velocity of the $\mathrm{CO}_{2}$ used for fluidization to a value sufficiently high to entrain the raw meal particles, but still sufficiently low that the coarse, inert particles are not entrained. The commercial CPFD software Barracuda was used for simulations to investigate suitable operational conditions at $1173 \mathrm{~K}$, such as the particle size distribution of the inert particles and the fluidization gas velocity. The impact of gas velocity variation on the fluidization of the particle mixture was studied, and an appropriate range of velocities for the calcination and entrainment modes could be determined. The simulations revealed that mixing raw meal particles with inert coarse particles can enhance the flowability in the FB reactor indicating that it is possible to apply the concept in a full-scale calcination process.
\end{abstract}

Keywords: electrification, fluidized bed, calciner, CPFD, Barracuda, limestone

\section{Introduction}

Concrete is the most consumed man-made material in the world, and cement is the binder in concrete. Cement plants produce 4 billion tonnes of cement per year, corresponding to 8 percent of the global anthropogenic $\mathrm{CO}_{2}$ emissions (Olivier et al., 2016). This makes the cement industry one of the main contributors to climate change. The main sources of $\mathrm{CO}_{2}$ emissions in the cement industry are attributed to the chemical and thermal combustion processes in the kiln system, where clinker is produced. Clinker is the main constituent in cement.

For reducing the $\mathrm{CO}_{2}$ emissions in the cement industry, different measures may be taken, such as 1) applying $\mathrm{CO}_{2}$ capture methods, 2) improving existing plans to recuperate thermal and electric efficiency, 3) replacing fossil fuels with $\mathrm{CO}_{2}$-neutral fuels, and 4) substituting clinker with alternative binders (Xu et al., 2014; Wang et al., 2018; Li et al., 2013).

Utilizing green electricity to produce clinker and applying an appropriate carbon capture technology to the reduction of $\mathrm{CO}_{2}$ emissions of the calcination process can be a good solution to mitigate the emissions of $\mathrm{CO}_{2}$ in the cement industry. Electrification of the calciner is most important because the calciner is the main source of $\mathrm{CO}_{2}$ in the cement kiln system (Tokheim et al., 2019).

Fluidized bed reactors have several advantages, such as high heat and mass transfer rate, good mixing properties, and close to isothermal conditions. Because of these advantages, the fluidization concept is widely used in different engineering applications, for example reforming of hydrocarbons, gasification, aluminium production, and calcination (Wang, 2015; Dechsiri, 2004; Cocco et al., 2014; Kunii and Levenspiel, 2013).

In an electrified calciner, the heat transfer will be area-limited. Hence, it is important to provide good contact between the meal and the hot surfaces in the calciner to obtain a high overall heat transfer coefficient. A fluidized bed may be a good reactor choice as FB's are characterized by good mixing and temperature control. Hence, in the current study, an electrically 
heated fluidized bed reactor is used to calcine the raw meal in the cement kiln process.

Experimental data and results from the simulation of a cold-flow lab-scale fluidized bed calciner have been compared in another paper (Ahmadpour Samani, 2020). The results revealed that owing to the vigorous interparticular forces in the Geldart $\mathrm{C}$ particles (constituting about $60 \%$ of the raw meal), it is difficult to fluidize the raw meal.

There are several methods to fluidize Geldart C particles, such as mixing them with coarser (Geldart B) particles (Kunii and Levenspiel, 2013; Tashimo et al., 1999; Kato, 1991), the mechanical agitation concept (using a chopper) (Kristensen and Schaefer, 1987; Chen et al., 2009), using Vibro-fluidization (Parikh, 2016; Chen et al., 2009), and applying a centrifugal field (Qian et al., 2001; Dave et al., 2007). In the current study, the method of mixing the small particles with inert, larger particles are investigated.

Based on experimental data and empirical observations, Geldart (Geldart, 1973) categorized particles into four types of particle behavior; A, B, C, and $\mathrm{D}$, depending on particle size and density difference between solids and the fluidization gas Geldart B particles are known as a particle category having excellent fluidization properties. The large interparticle forces of Geldart $\mathrm{C}$ will be decreased due to collisions with inert coarse particles, and thereby a more homogeneous distribution of the fine particles will be obtained, which may facilitate fluidization. Moreover, mixing the meal with coarser particles also has the advantage of providing a thermal reservoir for the meal to be calcined.

Such a system must be operated in two different modes: 1) the calcination mode, with a relatively low fluidization gas velocity and 2) the entrainment mode, with relatively high gas velocity. When operating in the calcination mode, all particles - both raw meal and inert particles - should be maintained in the reactor. In the entrainment mode, the gas velocity is increased sufficiently that the calcined particles are entrained by the gas and pulled out of the system, whereas the inert particles remain in the FB. When designing the FB reactor, it is necessary to i) make sure all particles are calcined before they leave the FB and ii) avoid loss of inert particles from the FB.

To investigate the potential fluidization improvement without having to do experiments, computational particle and fluid dynamics (CPFD) simulations have been performed. The purpose of the CPFD investigations are:

- Find out whether it is possible to operate such a system without significant losses of inert coarse particles while at the same time having sufficient time for calcination of the meal in the reactor
- Get a clearer picture of how the different particle types behave in the FB, and the way they interact with each other

The motivation of the work is to find a reactor concept that may be used to efficiently calcine cement raw meal, with pure $\mathrm{CO}_{2}$ as the only gaseous output from the reactor, hence avoiding the need for an expensive separation plant to capture the $\mathrm{CO}_{2}$ from the process.

\section{CPFD modelling and simulation}

The commercial CPFD software Barracuda was used to study the binary-particle fluidization system, consisting of fine raw meal particles and inert coarse particles, at a temperature of $1173 \mathrm{~K}$, which is the approximate calcination temperature in a full-scale system.

\subsection{The CPFD method}

The Barracuda Virtual Reactor, version 17.4.1, applies a numerical scheme based on the Eulerian-Lagrangian model in three dimensions for simulation of gas-particle flows. In the CPFD method, the gas phase is considered as a continuous fluid in a Eulerian grid of cells, and particles are considered as discrete Lagrangian points. The computational domain is divided into several computational parcels containing particles with the same velocity and properties. The Navier-Stokes equation is used for describing the gas phase, whereas the model of the solid phase is based on the multiphase particle-in-cell (MP-PIC) method, which is a Lagrangian description of particle motion (Andrews and O'Rourke, 1996; Snider and O’Rourke, 2011). Conservation equations for the momentum, mass, and energy are solved, including the coupling between the phases, and thereby the spatial distribution of key process parameters like temperature, pressure, and velocities in the system may be determined. Such information is necessary in order to understand the fluidization process, and that is why the CPFD scheme is widely used for simulation of gas-particle fluidized reactors (Jiang et al., 2014; Chen et al., 2013).

\subsection{Simplifications}

In the simulation of the binary-particle FB system in Barracuda, some simplifications have been made:

- Chemical reactions are not considered (the focus is on understanding the flow behaviour of the different particle types)

- An isothermal tubular vessel is used, i.e. no heating internals are applied in the dense bed

- The vessel is taken as adiabatic (i.e. heat loss is neglected)

The simplifications mentioned above will clearly give deviations between to the simulated results and data from an experimental system that includes heat transfer, chemical reactions and inserts. For example, chemical 
reactions will change the envelope density of the particles as well as the gas flow through the bed. Furthermore, any kind of insert in the dense bed will affect the hydrodynamics of the bed and probably increase the pressure drop over the bed. process is inherently dynamic, hence dynamic (time-dependent) equations are used. However, to facilitate comparison with the results reported in another paper by the authors (Ahmadpour Samani, 2020), the same geometry is used in the current study.

The system is simulated from the initial conditions until achieving a pseudo-steady state condition.

\subsection{Procedure to implement the CPFD model}

In order to start developing a CPFD model, a computeraided design $\left(\mathrm{CAD}^{1}\right)$ model with stereolithography $\left(\mathrm{STL}^{2}\right)$ format, which contains the geometry of the model should be prepared. For this purpose, the SolidWorks ${ }^{\circledR}$ software was used to generate the geometry of the cold-flow lab-scaled fluidized bed unit, as was also explained in another paper by the authors (Ahmadpour Samani, 2020). Next, the grid, which defines the spatial resolution for calculation of the important gas-particle flow properties including pressure, velocity, and temperature, was defined. Figure 1 represents the generated grid of the cold flow lab scaled fluidized bed unit.

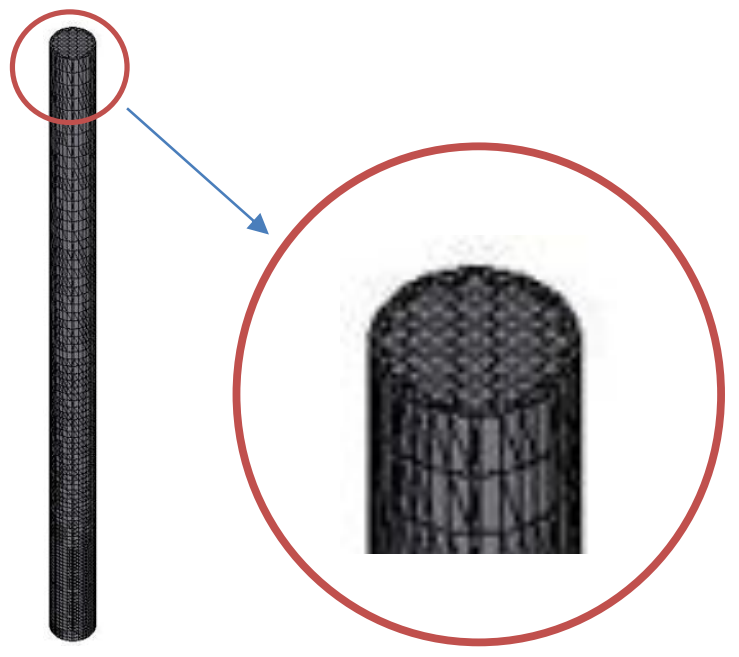

Figure 1. Grid and original CAD geometry

\subsubsection{Drag model}

Different built-in drag models are available in the Barracuda package, where detailed information about different drag models with references are explained in the Barracuda manual (Barracuda Virtual Reactor user manual, 2017). Since with applying the Wen \& Yu drag model, previous studies of CPFD simulations of bubbling fluidized bed gasifiers have shown a good

\footnotetext{
${ }^{1}$ CAD software is used to create two-dimensional drawings or three-dimensional models for engineering applications.
}

consistency with experimental results (Jaiswal et al., 2020; Furuvik et al., 2019; Furuvik et al., 2019), the Wen-Yu drag model has been chosen for the simulations of this study.

The fluid drag force on the particle can be calculated by equation (1).

$$
F_{p}=m_{p} D\left(u_{f}-u_{p}\right)
$$

In equation (1), $D$ defines as the drag function as shown in equation (2).

$$
D=\frac{3}{8} C_{d} \frac{\rho_{f}\left(u_{f}-u_{p}\right)}{\rho_{p} r_{p}}
$$

$C_{d}$, the drag coefficient is determined by different correlations in different drag models. The Ergun drag model is applied for dense systems, while Wen-Yu is appropriate for dilute systems (Barracuda Virtual Reactor user manual, 2017).

Equation (3) is the correlation for $C_{d}$ in the Wen-Yu drag model.

$$
C_{d}=\left\{\begin{array}{lr}
\frac{24 \theta_{f}^{n_{0}}}{R e} & R e<0.5 \\
\left(C_{d}\right)_{1} & 0.5 \leq R e \leq 1000 \\
c_{2} \theta_{f}^{n_{0}} & R e>10000
\end{array}\right.
$$

In this correlation, $\theta_{f}$ is the fluid volume fraction and the $R e$ number is defined by equation (4).

$$
\begin{gathered}
R e=\frac{2 \rho_{f} r_{p}\left|u_{f}-u_{p}\right|}{\mu_{f}} \\
\left(C_{d}\right)_{1}=\frac{24}{R e} \theta_{f}^{n_{0}}\left(c_{0}+c_{1} R e^{n_{1}}\right)
\end{gathered}
$$

The model constants are: $c_{0}=1.0, c_{1}=0.15, c_{2}=$ $0.44, n_{0}=-2.65$ and $n_{1}=0.687$

\subsubsection{Initial and boundary condition as well as flux planes and transient data}

Establishing the initial and boundary conditions are the succeeding step after the grid generation. In order to simulate the binary-particle fluidization system, two different types of particles are defined: $\mathrm{CaCO}_{3}$ as raw meal and silica sand $\left(\mathrm{SiO}_{2}\right)$ as inert coarse particles. $\mathrm{CO}_{2}$ was used as the fluidization gas.

The particle size of the raw meal particles ranged from 0.2 to $180 \mu \mathrm{m}$, whereas the inert coarse particles had a diameter in the range $550-800 \mu \mathrm{m}$.

The densities of fluidized gas and particles are listed in Table 1.

Figure 2 shows the positions of the inert particles (silica sand) and raw meal (limestone) particles in the Geldart diagram.

Figure 3 (a) shows the initial conditions in the system applied to determine a suitable fluidization velocity

\footnotetext{
${ }^{2} \mathrm{STL}$ is a file format of a 3-D model produced by CAD software.
} 
(more about this in section 3.2). The initial mass of $\mathrm{CaCO}_{3}$ (raw meal; blue) and $\mathrm{SiO}_{2}$ (silica sand; red) in the cylinder was 0.856 and $0.659 \mathrm{~kg}$ respectively. Identical layer thicknesses were used for raw meal and silica sand, but due to the difference in densities, the mass ratio was 13:10.

Figure 3 (b) shows the initial conditions in the system that corresponds to a 1:10 mass ratio between small and large particles. Initially, there were three thin layers of $\mathrm{CaCO}_{3}$ (blue) and three thicker layers of silica sand (red) in the dense bed. This mass ratio was used based on the paper of (Tashimo et al., 1999). Initially, i.e. before the gas was injected, the particles were at ease in the dense bed.

Figure 3 (c) illustrates the boundaries. As for the boundary conditions, different superficial gas velocities were applied (more about this in section 3 ). The outlet was defined as a pressure outlet with a pressure of $1 \mathrm{bar}$, i.e., atmospheric pressure.

As the system is isothermal and adiabatic, the purpose of setting the temperature to $900{ }^{\circ} \mathrm{C}$ is to determine the right values of the thermochemical properties, such as the viscosity, which is one of the key input parameters in the drag functions.

Transient data points were used to log the system pressure at the same locations as in the cold flow labscaled fluidized bed unit. Figure 3(d) shows the positions of these points.

A flux plane was determined on the top of the cylinder to calculate the values of particle entrainment. Figure 3(e) shows the location of the flux plane in Barracuda.

Table 1. Temperature and density of gas and particles

\begin{tabular}{|l|c|c|}
\hline Medium & $\begin{array}{c}\text { Temperature } \\
{\left[{ }^{\circ} \mathrm{C}\right]}\end{array}$ & $\begin{array}{c}\text { Envelope } \\
\text { Density } \\
{\left[\mathrm{kg} / \mathrm{m}^{3}\right]}\end{array}$ \\
\hline $\mathrm{CO}_{2}$ & 900 & 0.45 \\
\hline $\begin{array}{l}\mathrm{CaCO}_{3} \\
\text { (raw meal particles) }\end{array}$ & 20 & 2795 \\
\hline $\begin{array}{l}\text { Silica sand } \\
\text { (inert particles) }\end{array}$ & 20 & 2200 \\
\hline
\end{tabular}

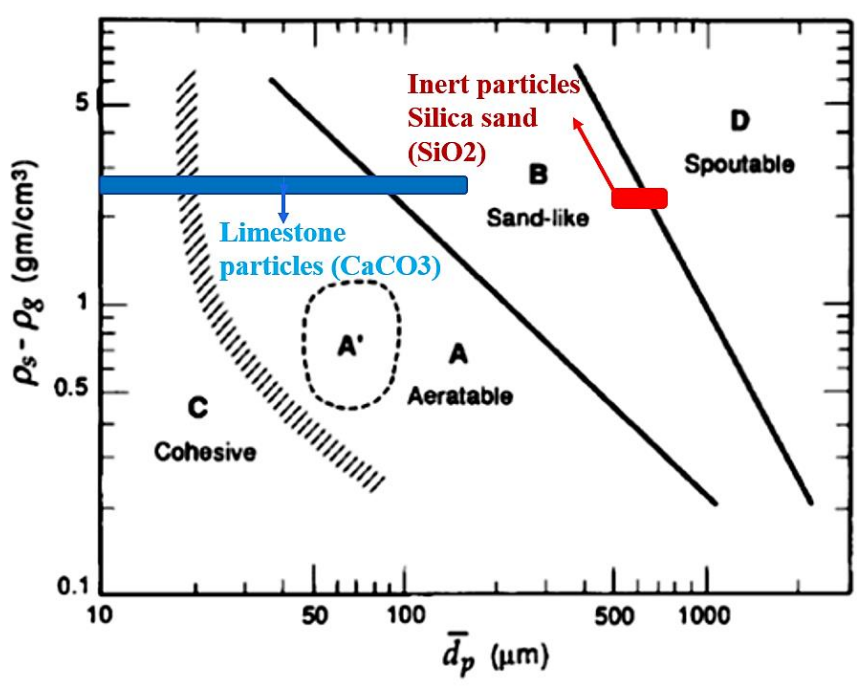

Figure 2. Geldart classification of particles for air at ambient conditions (Kunii and Levenspiel, 2013)

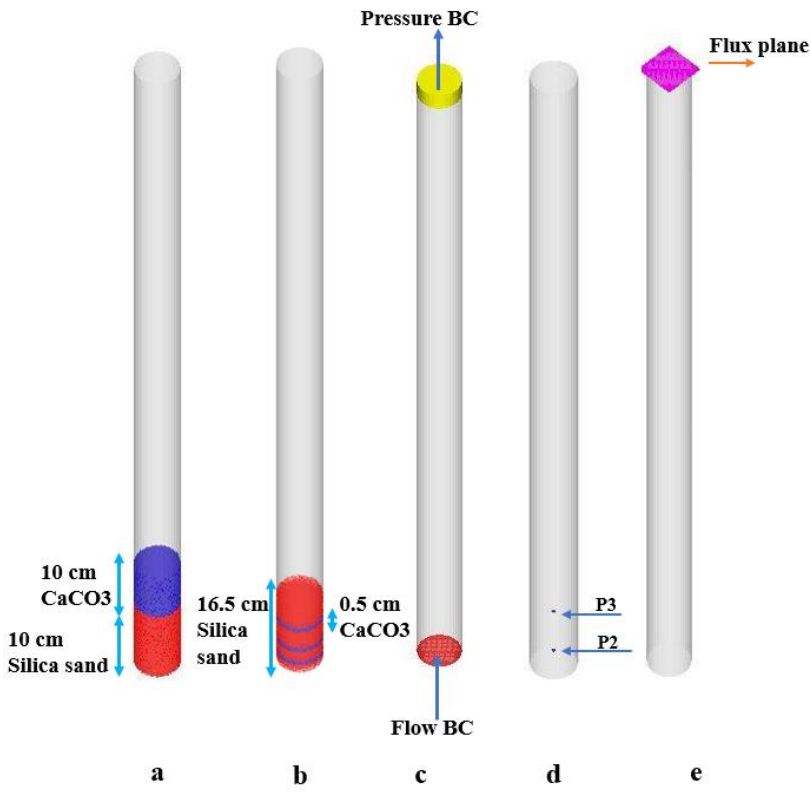

Figure 3: a, b) initial conditions, c) boundaries and d) transient points, e) Flux plane

\subsubsection{Time step and duration setting}

The system is simulated from $\mathrm{t}=0$ (initial conditions) until a pseudo-state has been reached. Pseudo-steady state is achieved when there is no longer any net change in mass flow out of the reactor. The pseudo-steady state is checked by calculating the entrainment flux of particles through the determined flux plane (Figure 3 (e)). The simulations were conducted for $120 \mathrm{~s}$ of process time.

In general, for CPFD simulations, the smaller the time step, the more accurate is the solution. However, applying small time steps also results in increased calculation time. In this study, a time step of $5 \mathrm{~ms}$ was applied as a reasonable trade-off between accuracy and computational time. 


\section{Results and discussion}

The minimum fluidization velocities were calculated by Wen-Yu equations for minimum fluidization velocity (Wen and Yu, 1966; Anantharaman et al., 2018). The terminal settling velocities of the particles were manually calculated by using the equations presented in (Zevenhoven and Kilpinen, 2001) and are listed in Table 2.

Table 2. The minimum fluidization velocity and terminal velocity (for the median particle size) of inert particles

\begin{tabular}{|c|c|c|}
\hline $\mathrm{D}_{\mathrm{p}}[\mu \mathrm{m}]$ & $\mathrm{V}_{\mathrm{mf}}[\mathrm{m} / \mathrm{s}]$ & $\mathrm{V}_{\mathrm{t}}[\mathrm{m} / \mathrm{s}]$ \\
\hline 550 & 0.09 & 2.6 \\
\hline 600 & 0.10 & 2.9 \\
\hline 650 & 0.12 & 3.1 \\
\hline 700 & 0.14 & 3.4 \\
\hline 750 & 0.16 & 3.7 \\
\hline 800 & 0.18 & 3.9 \\
\hline
\end{tabular}

\subsection{Reaction time based on the particle size}

In order to calculate the reaction time of raw meal particles based on the particle size distribution, the correlations and results of the paper (Stanmore and Gilot, 2005) have been utilized. According to Stanmore et al (Stanmore and Gilot, 2005), a model based on a modified shrinking core approach (Takkinen et al., 2012) was applied for limestone particles. The shrinking core model is widely used in the description of the kinetics of limestone reactions. This model demonstrates conditions in which solid particles are being emaciated either by dissolution or reaction and, as a result, the amount of the material being consumed is "shrinking".

The calcination conversion factor can be calculated by equation (6), where $k\left[\frac{m^{0.6}}{s}\right]$ is the kinetic rate for the reaction, $d_{p}[\mathrm{~m}]$ is particle diameter and $t[\mathrm{~s}]$ is reaction time.

$$
X=1-\left(1-\frac{k}{d_{p}^{0.6}} t\right)^{3}
$$

The value of $k$ is given by equation (7). In this equation, $T[\mathrm{~K}]$ is the temperature of the reaction.

$$
k=10.303 \exp \left(\frac{-10980}{T}\right)
$$

Hence, by applying equations (6) and (7), and assuming the values $X=0.94$ and $T=1173 \mathrm{~K}$, the reaction time of the calcination process based on the particle sizes of the raw meal has been calculated and shown in Figure 4. It is clear from Figure 4 that the reaction time for the majority of the small raw meal particles is very short ( $<1 \mathrm{~s})$, hence will likely be calcined before they are entrained and leave from the top of the FB. The larger meal particles may remain in the bed during the calcination mode so that they may be sufficiently calcined before the operation is shifted to entrainment mode.

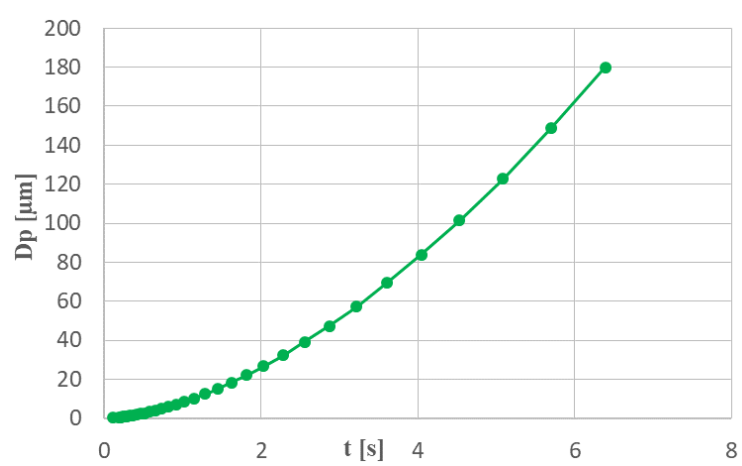

Figure 4. Reaction time for different particle sizes of limestone

\subsection{The velocity range of calcination mode}

Suitable operational conditions in the calcination mode must be determined. The low velocity in the calcination mode is determined in such a way that the most of the raw meal particles and all inert particles are fluidized and only a relatively small fraction of the raw meal is entrained by the gas. Barracuda is applied to find the appropriate velocity for the fluidization of the particles during the calcination mode. The velocity determined via simulation results may then be applied to design the FB reactor as an electrically heated reactor.

Figure 5 shows the minimum fluidization velocity and the terminal settling velocity of the two-particle types for different sizes (logarithmic scale). In the calcination mode, the gas velocity must be higher than the minimum fluidization velocity of the mixture but should (if possible) be lower than the terminal settling velocity of the finest particles. By using the velocity window in Figure 5, and according to the minimum fluidization velocity of the inert particles, the calcination mode velocity should be higher than the minimum fluidization velocity of the mixture, $0.13 \mathrm{~m} / \mathrm{s}$, so as to fluidize both raw meal and inert particles. Different velocities were tested in Barracuda, and the mass loss values at different velocities could be calculated using the flux plane file from the Barracuda simulation.

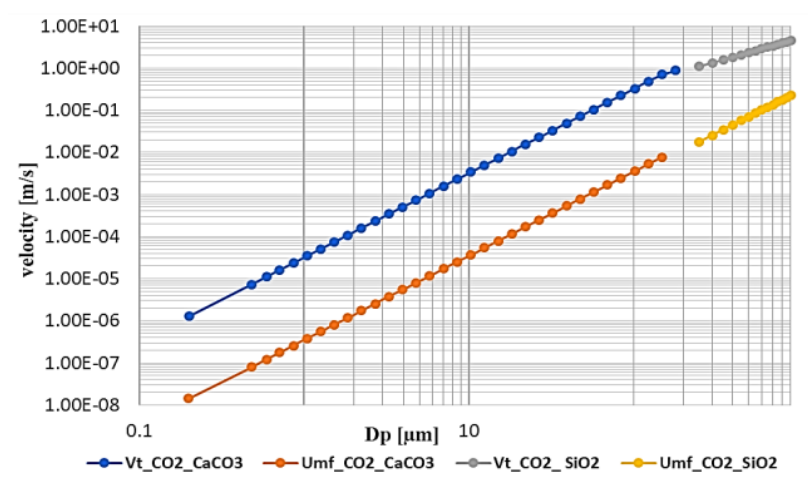

Figure 5. Velocity window for $\mathrm{CO}_{2}$ based on different particle sizes 
Table 3 shows the results for two different velocities. The simulations represented $120 \mathrm{~s}$ of process time. A gas velocity of $0.18 \mathrm{~m} / \mathrm{s}$, i.e. slightly higher than the minimum fluidization velocity, was selected to ensure that the particles would be fluidized. With this velocity, only $7.6 \%$ of the raw meal was entrained, and this velocity is to be used for the design of the FB reactor.

Table 3. The values of entrained mass in the calcination mode for a mass ratio of $1: 1$

\begin{tabular}{|l|l|l|l|l|l|}
\hline Case & $\begin{array}{l}\text { Velocity } \\
{[\mathrm{m} / \mathrm{s}]}\end{array}$ & $\begin{array}{l}\mathrm{CaCO}_{3} \\
\text { loss } \\
{[\mathrm{kg}]}\end{array}$ & $\begin{array}{l}\mathrm{CaCO}_{3} \\
\text { loss } \\
{[\%]}\end{array}$ & $\begin{array}{l}\mathrm{SiO}_{2} \\
\text { loss } \\
{[\mathrm{kg}]}\end{array}$ & $\begin{array}{l}\mathrm{SiO}_{2} \\
\text { loss } \\
{[\%]}\end{array}$ \\
\hline 1 & 0.18 & 0.065 & 7.6 & 0 & 0 \\
\hline 2 & 0.22 & 0.179 & 21 & 0 & 0 \\
\hline
\end{tabular}

Based on the results discussed above, the simulations with the ratio $1: 10$ were conducted at a velocity of 0.18 $\mathrm{m} / \mathrm{s}$. The initial mass of raw meal was $0.128 \mathrm{~kg}$, and at this velocity, only $2.8 \%$ of the meal left the cylinder. The results were calculated by using the data of the flux plane file in Barracuda and are listed in Table 4.

Table 4. The value of mass entrained at $0.18 \mathrm{~m} / \mathrm{s}$ with a mass ratio of $1: 10$

\begin{tabular}{|l|l|l|l|l|}
\hline $\begin{array}{l}\text { Velocity } \\
{[\mathrm{m} / \mathrm{s}]}\end{array}$ & $\mathrm{CaCO}_{3}$ & $\mathrm{CaCO}_{3}$ & $\mathrm{SiO}_{2}$ & $\mathrm{SiO}_{2}$ \\
& $l \mathrm{~kg}]$ & $l o s s$ & $l o s s$ & $l o s s$ \\
{$[\%]$} & {$[\mathrm{kg}]$} & {$[\%]$} \\
\hline 0.18 & $0.004 \mathrm{~kg}$ & 2.8 & 0 & 0 \\
\hline
\end{tabular}

Figure 6 depicts the fluidization and mixing of the raw meal (limestone, blue) and inert (silica sand, red) particles in the FB reactor. In the case with the ratio $1: 10$, the contact between raw meal and inert particles and heat transfer is increased. The inert particles also provide a thermal energy reservoir through their heat capacity and thereby contribute to a very stable bed temperature, which is advantageous in the control of the process. Hence, in the design of the FB reactor, a mass ratio of 1:10 may be suitable (although other mass ratios, somewhat higher or lower may also be considered).

Figure 6 also indicates that it takes as much as 30 seconds before most of the raw meal particles have reached the top of the dense bed. Considering the required time for calcination shown in Figure $4(<7$ seconds), this indicates that sufficient heat will have been transferred from the large, inert sand particles to the small raw meal particles so that it is likely that they will have been sufficiently calcined during the contact period.

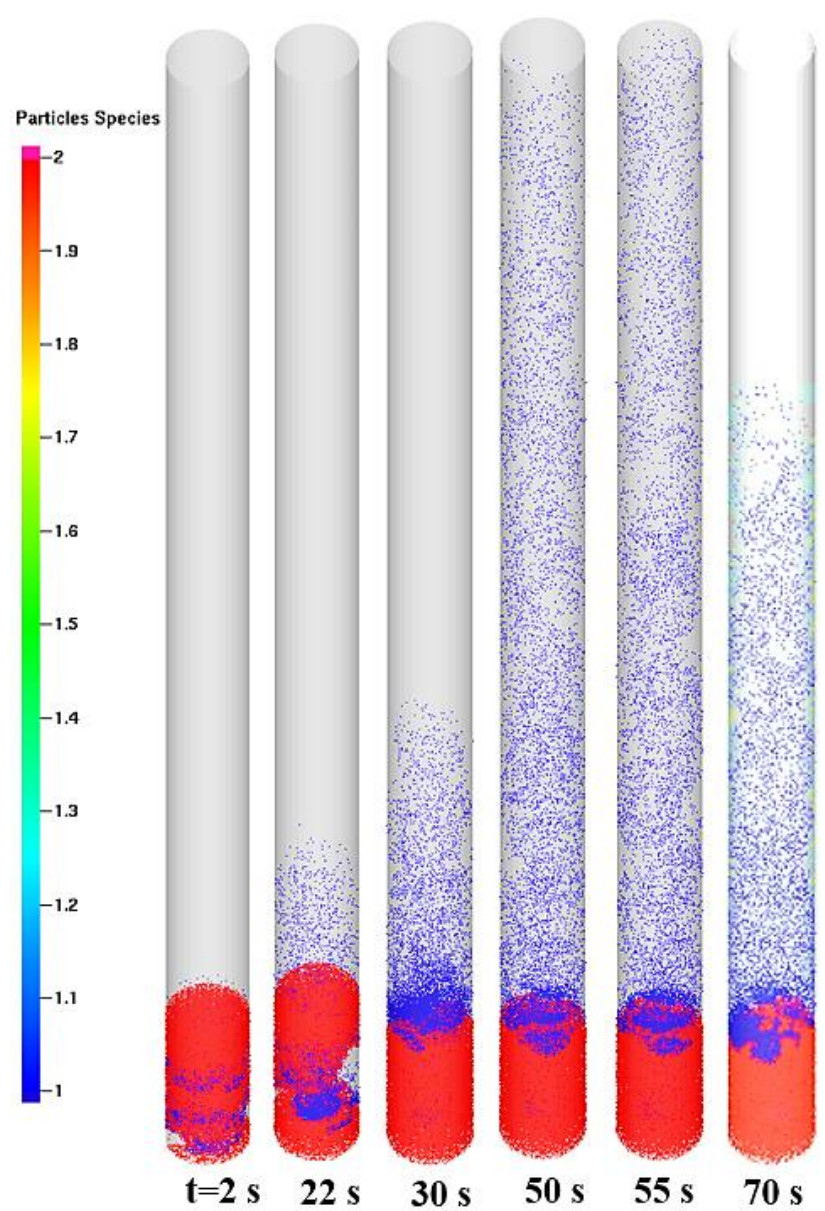

Figure 6. Distribution of limestone and silica sand particles with the ratio $1 / 10$ at different periods, $\mathrm{v}=0.18 \mathrm{~m} / \mathrm{s}$

\subsection{The appropriate gas velocity for entrainment stage}

When the calcination process is close to complete and the calcination degree reaches $94 \%$, the gas velocity will be increased to a high value, so that the calcined meal particles (but not the inert coarse particles) will be entrained from the bed. The velocity of the entrainment stage must be higher than the terminal settling velocity of the fine raw meal particles, but lower than the terminal settling velocity of the inert coarse particles. According to the data in Figure 5, the velocity can be between 0.9 and $3.2 \mathrm{~m} / \mathrm{s}$.

In order to find an appropriate gas velocity in the entrainment stage, different cases with the same initial height of raw meal and inert particles have been simulated. In Table 5, two cases with velocities of 1.5 $\mathrm{m} / \mathrm{s}$ and $3 \mathrm{~m} / \mathrm{s}$ are compared. With the velocity of $3 \mathrm{~m} / \mathrm{s}$, almost all raw meal particles were entrained from the bed, but no inert particles left the bed. Therefore, a velocity of $3 \mathrm{~m} / \mathrm{s}$ in the entrainment stage is seen as appropriate. The data has been obtained by applying the flux plane file of Barracuda. The simulations were conducted for $120 \mathrm{~s}$. 
Table 5. The values of the entrained mass of raw meal and inert particles in the entrainment stage

\begin{tabular}{|l|l|l|l|l|l|}
\hline Case & $\begin{array}{l}\text { Velocity } \\
{[\mathrm{m} / \mathrm{s}]}\end{array}$ & $\begin{array}{l}\mathrm{CaCO}_{3} \\
\text { loss } \\
{[\mathrm{kg}]}\end{array}$ & $\begin{array}{l}\mathrm{CaCO}_{3} \\
\text { loss } \\
{[\%]}\end{array}$ & $\begin{array}{l}\mathrm{SiO}_{2} \\
\text { loss } \\
{[\mathrm{kg}]}\end{array}$ & $\begin{array}{l}\mathrm{SiO}_{2} \\
\text { loss } \\
{[\%]}\end{array}$ \\
\hline 1 & 1.5 & 0.659 & 77 & 0 & 0 \\
\hline 2 & 3.0 & 0.850 & 99 & 0 & 0 \\
\hline
\end{tabular}

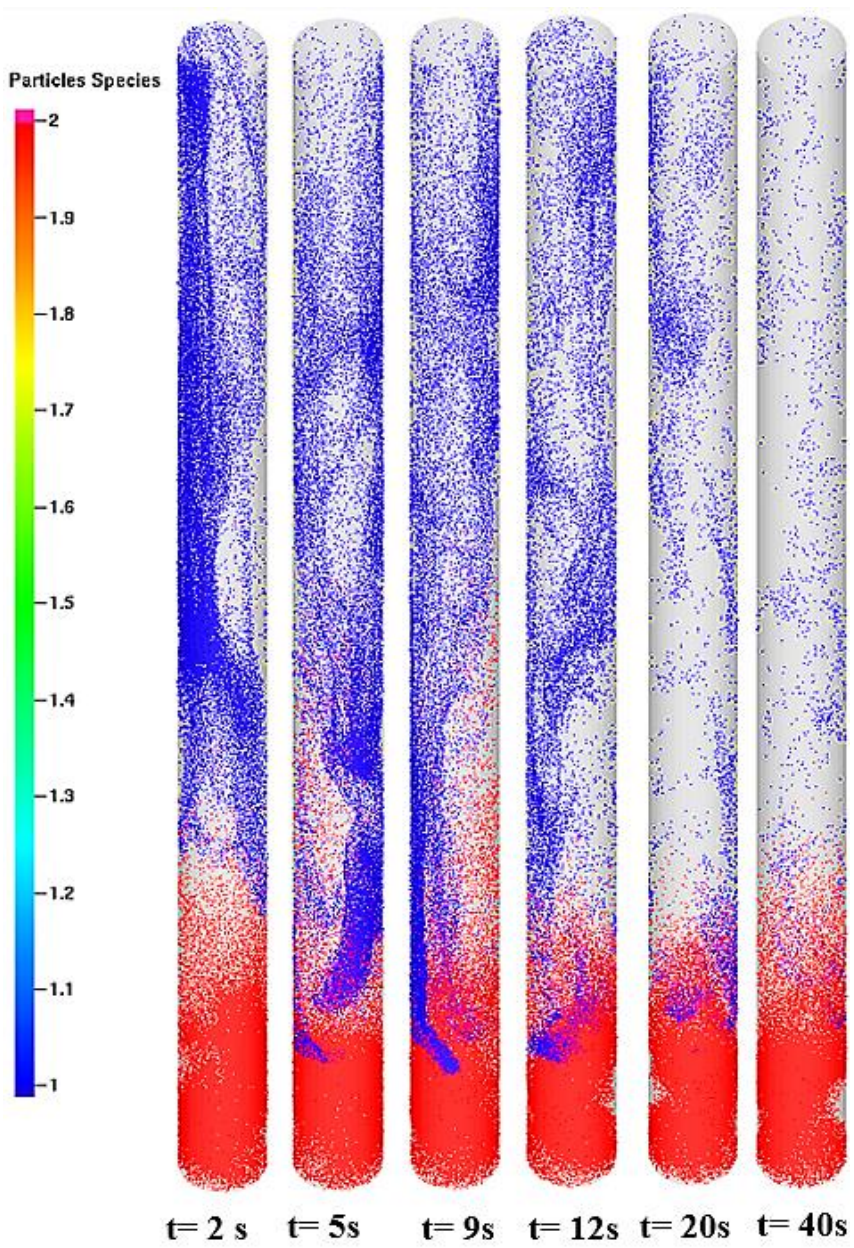

Figure 7. The distribution of raw meal and inert particles in the entrainment stage

As can be seen in Figure 7, at the gas velocity of 3 $\mathrm{m} / \mathrm{s}$, the raw meal particles left the bed, but the inert particles remained in the bed. After entrainment of the calcined meal, the bed is ready for a new calcination period.

\section{Conclusion}

To enhance the fluidization of the raw meal particles (0.2-180 $\mu \mathrm{m}$; i.e. Geldart C), mixing them with inert coarse particles $(550-800 \mu \mathrm{m}$; i.e. Geldart B) was proposed.

Such mixing tends to counteract the interparticular forces in the Geldart $\mathrm{C}$ powder. Another advantage is that the Geldart B particles provide a thermal energy reservoir through their heat capacity and thereby contribute to a stable bed temperature.

Barracuda was used for CPFD simulations to determine a suitable operational gas velocity at $1173 \mathrm{~K}$. The inert coarse particles were found to have an average minimum fluidization velocity of $0.129 \mathrm{~m} / \mathrm{s}$ and a terminal settling velocity of $3.24 \mathrm{~m} / \mathrm{s}$. The appropriate velocities for the calcination and entrainment modes were determined as $0.18 \mathrm{~m} / \mathrm{s}$ and $3 \mathrm{~m} / \mathrm{s}$ for a mass ratio of $1: 10$ between raw meal and sand particles. Based on literature results, this is believed to be a suitable mass ratio.

The simulations illustrated that at the velocity of 0.18 $\mathrm{m} / \mathrm{s}$ (calcination velocity), with the $1: 10$ mass ratio, only $2.8 \%$ of the raw meal particles were lost from the bed during the calcination period. At the velocity of $3 \mathrm{~m} / \mathrm{s}$ (entrainment velocity), $99 \%$ of the raw meal particles were entrained, while no inert particles were entrained. Hence, it is possible to operate the system with an appropriate separation efficiency during the entrainment period.

The calculated reaction time of the limestone particles revealed that limestone particles in the diameter range of $0.2-70 \mu \mathrm{m}$ were calcined in the time range $0.1-3.7 \mathrm{~s}$. Therefore, they are likely to be calcined before leaving the reactor in the calcination mode.

The simulations indicate that it is feasible to enhance the flowability of raw meal in the FB reactor by mixing them with the inert silica sand particles. The results also indicate that it is possible to obtain sufficient calcination of the raw meal particles during the calcination period and a high degree of separation during the entrainment period. This means that the concept should be possible to apply in a full-scale calcination process.

In future work, the calcination process will be simulated for a full-scale system including heat transfer and chemical reactions.

\section{References}

N. Ahmadpour Samani, Ch. K. Jayarathna, and L.A. Tokheim. Fluidized bed calcination of cement raw meal: Laboratory experiments and CPFD simulations, In Proceedings, 61th SIMS conference, 22-24 September, Finland, 2020.

A. Anantharaman, R. A. Cocco, and J. W. Chew. Evaluation of correlations for minimum fluidization velocity (Umf) in gassolid fluidization, Powder technology, 323: 454-85, 2018.

M. J. Andrews and P. J. O'Rourke. The multiphase particle-in-cell (MP-PIC) method for dense particulate flows, International Journal of Multiphase Flow, 22: 379-402, 1996.

C. Chen, J. Werther, S. Heinrich, H. Y. Qi, and E. Ulrich. CPFD simulation of circulating fluidized bed risers. Powder technology Hartge, 235: 238-47. 2013.

Y. Chen, J. Yang, R. N. Dave, and R. Pfeffer. Granulation of cohesive Geldart group $\mathrm{C}$ powders in a Mini-Glatt fluidized bed by pre-coating with nanoparticles, Powder technology, 191: 206-17, 2009.

R. Cocco, S. R. Karri, and T. Knowlton. Introduction to fluidization, Chem. Eng. Prog, 110: 21-29, 2014. 
Barracuda Virtual Reactor user manual. Houston, USA, 2017. https://cpfd-software.com

R. Dave, R. Pfeffer, J. Yang, and Y. Chen. Dry coating and downstream processing of cohesive powders. In.: Google Patents, 2007.

Ch. Dechsiri. Particle transport in fluidized beds, University Medical Center Groningen, University of Groningen, 2004.

N. C. I. Furuvik, R. Jaiswal, and B. M. E. Moldestad. Flow behavior in an agglomerated fluidized bed gasifier, The International Journal of Energy and Environment, 10 (2), 5564, 2019.

N. C. I. Furuvik, R. Jaiswal, R. K. Thapa, and B. M. E. Moldestad. CPFD model for prediction of flow behavior in an agglomerated fluidized bed gasifier, Int. J. of Energy Prod. \& Mgmt, 2019.

D. Geldart. Types of gas fluidization, Powder technology, 7: 28592, 1973.

R. Jaiswal, N.C. I. Furuvik, R. K. Thapa, and B. M. E. Moldestad. Method of identifying an operating regime in a bubbling fluidized bed gasification reactor, International Journal of Energy Production and Management, 5: 24-34, 2020.

Y. Jiang, G. Qiu, and J. Haigang. Modelling and experimental investigation of the full-loop gas-solid flow in a circulating fluidized bed with six cyclone separators, Chemical Engineering Science Wang. 109: 85-97, 2014

K. Kato. Residence time distribution of fine particles in a powderparticle fluidized bed, Kagaku Kogaku Ronbunshu, 17: 970-75, 1991.

H. G. Kristensen and T. Schaefer. Granulation: a review on pharmaceutical wet-granulation, Drug development and industrial pharmacy, 13: 803-72, 1987.

D. Kunii and O. Levenspiel. Fluidization engineering. Elsevier, 2013.

J. Li, P. Tharakan, D. Macdonald, and J. Xi. Technological, economic and financial prospects of carbon dioxide capture in the cement industry, Energy Policy Liang, 61: 1377-87, 2013.

J. Olivier, G. J. Maenhout, M. Muntean, and J. Peters. Trends in global CO2 emissions; 2014 Report, PBL Netherlands Environmental Assessment Agency; European Commission, Joint Research Centre, Ispra, Italy, 2016.

D. M. Parikh. Handbook of pharmaceutical granulation technology, CRC Press. 2016.

G. H. Qian, I. Bágyi, I. W. Burdick, R. Pfeffer, H. Shaw, and J. G. Stevens. Gas-solid fluidization in a centrifugal field, AIChE Journal, 47: 1022-34. 2001

D. M. Snider and P. J. O'Rourke. The multiphase particle-in-cell (MP-PIC) method for dense particle flow. Computational GasSolids Flows and Reacting Systems: Theory, Methods and Practice (IGI Global), 2011.

B. Stanmore and P. Gilot. calcination and carbonation of limestone during thermal cycling for $\mathrm{CO} 2$ sequestration, Fuel processing technology, 86: 1707-43, 2005.

S. Takkinen, J. Saastamoinen, and T. Hyppänen. Heat and mass transfer in calcination of limestone particles, AIChE Journal, 58: 2563-72, 2012.

T. Tashimo, T. Suto, J. Murota, and K. Kato. Calcination of fine limestone particles by a powder-particle fluidized bed, Journal of chemical engineering of Japan, 32: 374-78, 1999.

L. A. Tokheim, A. Mathisen, L. E. Øi, Ch. Jayarathna, N. H. Eldrup, and T. Gautestad. Combined calcination and $\mathrm{CO} 2$ capture in cement clinker production by use of electrical energy. TCCS-10. CO2 Capture, Transport and Storage. Trondheim 17th-19th June 2019. Selected papers from te 10th International Trondheim CCS Conference. pages 101-109, 2019.
H. Wang, W. Chen, and J. Jingcheng. Low carbon transition of global building sector under 2-and 1.5-degree targets, Applied energy. 2018222: 148-57, 2018.

M. Wang. Industrial tomography: systems and applications. Elsevier. 2015

C. Wen and $\mathrm{Y}$. Yu. A generalized method for predicting the minimum fluidization velocity, AIChE Journal, 12: 610-12, 1966.

J. H. Xu, T. Fleiter, Y. Fan, and J. Wolfgang. CO2 emissions reduction potential in China's cement industry compared to IEA's Cement Technology Roadmap up to 2050, Applied Energy Eichhammer, 130: 592-602, 2014.

R. Zevenhoven and P. Kilpinen. Control of pollutants in flue gases and fuel gases. Helsinki University of Technology Espoo, Finland, 2001. 